\title{
The influence of the genotype of Lolium perenne on homoeologous chromosome association in hexaploid Festuca arundinacea
}

\author{
G. M. Evans and Taing Aung
}

Department of Agricultural Botany, University

College of Wales, Aberystwyth, Dyfed, U.K.

The pattern of chromosome association at first metaphase of meiosis in interspecific hybrids of the natural hexaploid Festuca arundinacea and the diploid Lolium perenne was examined in order to investigate the relationship between a pairing control system previously isolated in $L$. perenne and that present in the hexaploid $F$. arundinacea. The pairing pattern at meiosis in the hybrids was clearly modified by the genotype of $L$. perenne and by the presence of $B$ chromosomes. Whereas chromosome association (homoeologous) in $F$. arundinacea $\times L$. perenne genotype Lp10 without B chromosomes was extensive it was almost absent in the hybrids involving $L$. perenne genotype Lp19 containing B chromosomes. Two alternative interpretations are suggested for the relationship between the two pairing control systems.

\section{INTRODUCTION}

Allopolyploid species are a common feature of many genera of flowering plants. Stebbins (1938) estimated that 30 to 35 per cent of all Angiosperm species are of this type. It is particularly common amongst crop plants with wheat, oats, cotton, tobacco, groundnut, sugar cane, oil seed rape and many of the forage grasses being important examples. It is now generally accepted that the stability and fertility of these natural interspecific polyploids is maintained by a genetic system which ensures that only homologous chromosomes form chiasmate associations at meiosis. They therefore behave cytologically as diploids which in turn ensures regular disjunction of chromosomes at anaphase one of meiosis and chromosome stability in the progeny. Moreover inheritance is disomic thus maintaining the interspecific hybridity of the genotype.

The genetic system controlling chromosome pairing in wheat was originally described by Okamoto (1957), Riley and Chapman (1958) and Sears and Okamoto (1958). This has been updated by a number of workers since that time but the basic principle is unchanged. This is that control is largely although not completely due to the effect of a gene (or genes) on chromosome 5B and which subsequently has been termed the $P h$ gene (Riley,
Wall and Gale, 1971). There is also evidence of comparable genetic systems in hexaploid oats (Gauthier and McGinnis, 1968; Rajhathy and Thomas, 1972) and possibly in hexaploid Festuca arundinacea (Jahuar, 1975). Little is known of the origin of these systems although genotypes of related diploids have been identified as being capable of suppressing the ability of these regulatory genes to modify meiosis in the polyploid (Riley, Kimber and Chapman, 1961; Dover and Riley, 1972a; Rajhathy and Thomas, 1972). However this does not prove that the genes carried by the diploids are allelic to those in the natural allopolyploids. Indeed there is evidence that the gene or genes within Aegilops speltoides ( $=$ Triticum speltoides) which are capable of nullifying the diploidising effect of the $P h$ gene of $T$. aestivum are not equivalent to the $P h$ gene and are not capable of compensating for its absence (Dover and Riley, 1972b).

B chromosomes are also known to suppress homoelogous association of chromosomes at first metaphase of meiosis (Evans and Macefield, 1972; Dover and Riley, 1972b; Bowman and Thomas, 1973; Riley, Chapman and Miller, 1973; Taylor and Evans, 1977; Evans and Davies, 1983). That their action is somewhat similar to that of the $P h$ system in wheat is suggested by the results of Dover and Riley (1972b). B chromosomes from 
Ae. mutica and Ae. speltoides were shown to compensate for the absence of $P h$ by suppressing homoeologous association in nulli-5B $T$. aestivum $\times$ Aegilops hybrids.

The present paper describes the results of crosses between the natural allohexaploid Festuca arundinacea $(2 n=6 x=42)$ and two diploid genotypes of Lolium perenne both of which carried a single B chromosome. Although half sibs these two genotypes of $L$. perenne have been shown to have a markedly different effect on chiasmate association of homoeologous chromosomes in both diploid and induced tetraploids hybrids with L. temulentum (Taylor and Evans, 1977; Evans and Davies, 1983). While Lp19 is capable of suppressing effective homoeologous association Lp10 is not. However the B chromosome in both genotypes does have a diploidising effect.

\section{MATERIALS AND METHODS}

Reciprocal crosses were made between plants from S.170 cultivar of Festuca arundinacea $(2 n=2 x=$ 42) and genotypes Lp10 and Lp19 of Lolium perenne. Details of the origin of $\mathrm{Lp} 10$ and $\mathrm{Lp} 19$ are given by Taylor and Evans (1977). It is worth emphasising however that they are half sibs derived from a single heterozygous $L$. perenne genotype containing $1 \mathrm{~B}$ chromosome outcrossed to a commercial cultivar called S.24. Both Lp10 and Lp19 have a chromosome complement of $2 n=2 x=$ $14+1 \mathrm{~B}$, the $\mathrm{B}$ chromosome having been inherited from the maternal parent and therefore being genetically identical in both genotypes. Crosses were made by emasculating a mature inflorescence of the seed parent before anthesis and enclosing it in a cellophane bag with several inflorescences of similar age from the pollen parent. At anthesis the bags were shaken several times per day to facilitate pollination. Immature embryos were cultured to the seedling stage on a simple agar based culture medium. Subsequently the plants were grown to maturity in soil.

Inflorescences were fixed in Carnoys $(6: 3: 1)$ fixative and stored until examined 1-3 months later. Squash preparations of pollen mother cells were made in the usual manner and 30 cells at metaphase one of meiosis scored where possible.

\section{RESULTS}

Over 100 hybrid plants were obtained when the diploid $L$. perenne was used as the seed parent. However all exhibited complete pistillody, i.e., the anthers were replaced by a structure which resembled a stigma and style. Consequently none of these hybrids could be examined at meiosis. This phenomenon is similar to that observed by Islam, Shepherd and Sparrow (1981) in some crosses of diploid Hordeum vulgare $\times$ hexaploid Triticum aestivum.

The reciprocal cross of $F$. arundinacea $\times L$. perenne yielded fewer progeny all of which had normal floral structures. Meiosis was examined in a total of 20 hybrid plants which could be divided into 4 classes on the basis of genotype of the $L$. perenne parent and the presence or absence of $\mathrm{B}$ chromosomes. The single $\mathrm{B}$ in both $L$. perenne genotypes would be expected to be transmitted into roughly half the pollen grains with consequent doubling through non disjunction at first pollen grain mitosis (Macefield, 1976). The progeny therefore either had 28 chromosomes or $28+2 \mathrm{~B}$ chromosomes. The frequencies of univalents, bivalents, trivalents, quadrivalents and chiasmata are given in table 1 with class means in table $2 \mathrm{a}$.

Clearly considerable variation exists in the pairing pattern of chromosomes at first metaphase both within and between classes. Despite the intraclass variation certain patterns of chromosome behaviour emerge. Chromosome pairing in the Lp10 hybrids is extensive, with that in the $0 \mathrm{~B}$ segregants being particularly high. In this class most of the chromosomes are involved in some form of chiasmate association (Fig. 1a and b). Although multivalents were not uncommon (Fig. 1a) bivalents nevertheless predominated. This is typified by the cell shown in fig. 1b where all the chromosomes have associated as bivalents. This in itself is somewhat surprising bearing in mind that the cross is between an allohexaploid and a diploid. That chromosomes of the four genomes in the hybrids are structurally differentiated is evident from the heteromorphic nature of many of the bivalents in these high pairing cells. At least 12 , possibly all 14 , bivalents in the metaphase complement shown in fig. $1 \mathrm{~b}$ are heteromorphic. This is particularly clear in the five rod bivalents.

At the other extreme there was very little chiasmate association of chromosomes in the pollen mother cells of many of the Lp19 hybrids containing $2 \mathrm{~B}$ chromosomes. Fig. $1 \mathrm{e}$ and $\mathrm{f}$ typify the almost complete absence of any chiasmate association at first metaphase. In the cell illustrated in fig. If all $28 \mathrm{~A}$ chromosomes are unpaired with only the $2 \mathrm{~B}$ chromosomes forming a bivalent. This was not uncommon in three out of the six hybrids in this class with one plant having a mean frequency of almost 26 univalents per pollen mother cell. 
Table 1 Mean frequencies of univalents, bivalents, trivalents, quadrivalents and chiasmata in pollen mother cells of hybrids

\begin{tabular}{|c|c|c|c|c|c|c|}
\hline \multirow[b]{2}{*}{ Hybrid } & \multirow{2}{*}{$\begin{array}{l}\text { Chromosome } \\
\text { Number }\end{array}$} & \multicolumn{5}{|c|}{ Mean number per pollen mother cell of } \\
\hline & & I & II & III & IV & Chiasmata \\
\hline \multicolumn{7}{|c|}{ S. $170 \times$ Lp10 } \\
\hline \multicolumn{7}{|c|}{ OB Segregants } \\
\hline 1 & 28 & $2 \cdot 13$ & $11 \cdot 37$ & $0 \cdot 60$ & $0 \cdot 33$ & $19 \cdot 80$ \\
\hline 2 & 28 & $3 \cdot 19$ & $8 \cdot 81$ & $1 \cdot 47$ & 0.66 & $19 \cdot 53$ \\
\hline 3 & 28 & $3 \cdot 43$ & $10 \cdot 47$ & 0.63 & $0 \cdot 43$ & $18 \cdot 23$ \\
\hline 4 & 28 & $3 \cdot 48$ & $9 \cdot 76$ & 1.08 & $0 \cdot 44$ & $18 \cdot 44$ \\
\hline 5 & 28 & $3 \cdot 75$ & $10 \cdot 95$ & $0 \cdot 25$ & $0 \cdot 40$ & $20 \cdot 30$ \\
\hline 6 & 28 & 4.93 & $8 \cdot 40$ & 1.47 & 0.47 & $17 \cdot 60$ \\
\hline 7 & 28 & $5 \cdot 20$ & $9 \cdot 35$ & 0.70 & 0.50 & $17 \cdot 25$ \\
\hline 8 & 28 & $11 \cdot 75$ & $6 \cdot 40$ & $1 \cdot 15$ & 0.00 & $11 \cdot 10$ \\
\hline \multicolumn{7}{|c|}{ 2B Segregants } \\
\hline 1 & $28+2 B$ & $4 \cdot 75$ & $8 \cdot 88$ & $1 \cdot 40$ & 0.33 & $16 \cdot 75$ \\
\hline 2 & $28+2 B$ & $5 \cdot 45$ & $8 \cdot 30$ & $1 \cdot 05$ & 0.70 & $15 \cdot 95$ \\
\hline 3 & $28+2 B$ & $12 \cdot 34$ & $7 \cdot 25$ & $0 \cdot 29$ & $0 \cdot 13$ & $10 \cdot 66$ \\
\hline 4 & $28+2 B$ & $13 \cdot 05$ & $6 \cdot 05$ & $0 \cdot 55$ & $0 \cdot 30$ & $9 \cdot 75$ \\
\hline \multicolumn{7}{|c|}{ S.170 $\times$ Lp19 } \\
\hline \multicolumn{7}{|c|}{ 0B Segregants } \\
\hline 1 & 28 & $9 \cdot 00$ & $8 \cdot 83$ & $0 \cdot 27$ & $0 \cdot 13$ & $13 \cdot 80$ \\
\hline 2 & 28 & $12 \cdot 96$ & $6 \cdot 57$ & 0.35 & $0 \cdot 28$ & $10 \cdot 48$ \\
\hline \multicolumn{7}{|c|}{ 2B Segregants } \\
\hline 1 & $28+2 B$ & $11 \cdot 73$ & $7 \cdot 60$ & $0 \cdot 13$ & $0 \cdot 17$ & $10 \cdot 70$ \\
\hline 2 & $28+2 B$ & $17 \cdot 70$ & $4 \cdot 85$ & $0 \cdot 20$ & 0.00 & $6 \cdot 70$ \\
\hline 3 & $28+2 B$ & $18 \cdot 87$ & $4 \cdot 47$ & 0.07 & 0.00 & $5 \cdot 63$ \\
\hline 4 & $28+2 B$ & $20 \cdot 50$ & $3 \cdot 60$ & $0 \cdot 10$ & 0.00 & $4 \cdot 20$ \\
\hline 5 & $28+2 B$ & 21.67 & $3 \cdot 17$ & 0.00 & 0.00 & $3 \cdot 88$ \\
\hline 6 & $28+2 B$ & $25 \cdot 66$ & $1 \cdot 14$ & 0.02 & 0.00 & $1 \cdot 30$ \\
\hline
\end{tabular}

Table 2 Univalents, bivalents, trivalents, quadrivalents and chiasmata in the hybrids (a) Mean values

\begin{tabular}{|c|c|c|c|c|c|}
\hline \multirow[b]{2}{*}{ Hybrid Class } & \multicolumn{5}{|c|}{ Mean number per pollen mother cell of } \\
\hline & I & II & III & IV & Chiasmata \\
\hline S. $170 \times \mathrm{Lp} 100 \mathrm{~B}$ & $4 \cdot 73$ & $9 \cdot 44$ & 0.92 & $0 \cdot 40$ & $13 \cdot 78$ \\
\hline $\mathrm{S} .170 \times \mathrm{Lp} 102 \mathrm{~B}$ & $8 \cdot 90$ & $7 \cdot 62$ & $0 \cdot 80$ & $0 \cdot 37$ & $13 \cdot 28$ \\
\hline $\mathrm{S} .170 \times \mathrm{Lp} 190 \mathrm{~B}$ & $10 \cdot 98$ & $7 \cdot 70$ & $0 \cdot 31$ & $0 \cdot 18$ & $12 \cdot 14$ \\
\hline S. $170 \times \mathrm{Lp} 192 \mathrm{~B}$ & $19 \cdot 35$ & $4 \cdot 14$ & 0.09 & $0 \cdot 03$ & $5 \cdot 40$ \\
\hline
\end{tabular}

(b) Analysis of variance

\begin{tabular}{|c|c|c|c|c|c|c|}
\hline Comparison & DF & I & II & $\begin{array}{l}\text { Mean Square } \\
\text { III }\end{array}$ & IV & Chiasmata \\
\hline Lp10/Lp19 & 1 & $69 \cdot 74^{*}$ & $6 \cdot 81 \dagger$ & $0.442 \dagger$ & $0.079 \dagger$ & $45 \cdot 68^{*}$ \\
\hline $0 \mathrm{~B} / 2 \mathrm{~B}$ & 1 & $39 \cdot 31^{*}$ & $7 \cdot 24 \dagger$ & 0.028 & 0.008 & $39 \cdot 60^{*}$ \\
\hline Interaction & 1 & $4 \cdot 43$ & 0.76 & 0.003 & 0.003 & $1 \cdot 24$ \\
\hline Error & 16 & $3 \cdot 85$ & 0.78 & 0.036 & 0.007 & $2 \cdot 49$ \\
\hline
\end{tabular}

$* \mathrm{P}=<0.001 \quad+\mathrm{P}=<0.01$

The S. $170 \times \mathrm{Lp} 10+2 \mathrm{Bs}$ and the S.170 $\times$ Lp19 OB hybrids appeared to have an intermediate level of pairing although the latter class was represented by only two plants. Typical complements are shown in fig. 1c and $\mathrm{d}$.

It appears therefore that both the genotype of the $L$. perenne parent and the presence or absence of B chromosomes influence the pairing pattern at meiosis in these hybrids. This is confirmed by a one way analysis of variance (table 2 ). In view of the different numbers of plants in each class the tests between classes was done on means with the overall error variance being corrected by using the harmonic mean. Although the analysis can be 
a

C

e

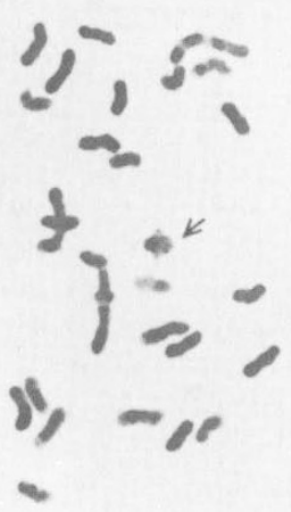

b

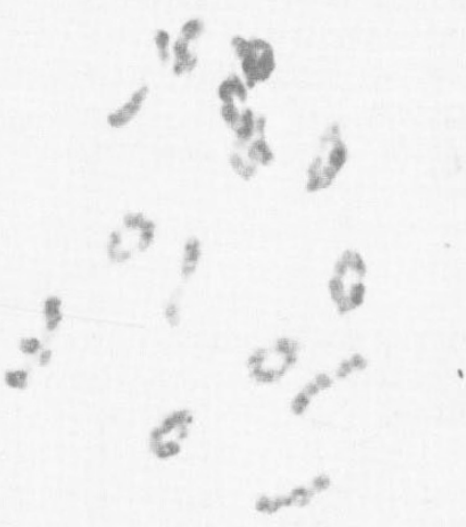

d

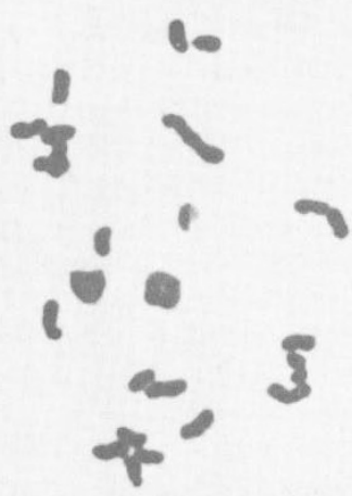

Figure 1 First metaphase of meiosis in pollen other cells of hybrids. a-c, S.170 $\times$ Lp10: (a) $0 \mathrm{~B}$ segregant, $2^{\mathrm{IV}}, 1^{\mathrm{III}}, 5^{\mathrm{II}}$ and $7^{\mathrm{I}}$; (b) $0 \mathrm{~B}$ segregant, $14^{\mathrm{II}}$; (c) $2 \mathrm{~B}$ segregant, $11^{\mathrm{II}}$ and $6^{\mathrm{I}}\left(+1^{\mathrm{II}} \mathrm{B}\right.$ arrowed). d-f, S.170 $\times$ Lp19: (d) $0 \mathrm{~B}$ segregant, $4^{\mathrm{II}}$ and $20^{\mathrm{I}}$; (e) $2 \mathrm{~B}^{\prime}$ segregant, $2^{\mathrm{II}}$ and $20^{\mathrm{I}}\left(+1^{\mathrm{II}} \mathrm{B}\right.$ arrowed); (f) $2 \mathrm{~B}$ segregant, $28^{\mathrm{I}}\left(+1^{\mathrm{II}} \mathrm{B}\right.$ arrowed).

questioned on the grounds of low replication in one class it still serves to confirm the overall pattern. This is that:

1. Progeny of the cross involving $L$. perenne Lp19 have a much higher number of unpaired (univalent) chromosomes and fewer bivalents, trivalents and quadrivalents per pollen mother cell than hybrids from the $L$. perenne Lp10 cross.

2. The frequency of univalents is also higher and that of bivalents lower in plants containing 
2B chromosomes when compared with those carrying $0 \mathrm{Bs}$ from the same cross.

3. There appears to be no interaction between L. perenne genotype and B chromosome status. Their effects can therefore be considered additive.

\section{DISCUSSION}

There is convincing evidence that $F$. arundinacea is an allohexaploid. In the first place only bivalents are normally found at first metaphase of meiosis and secondly inheritance is disomic (Lewis et al., 1980). The origin of the three genomes has never been clearly established although it is generally believed that $F$. pratensis and possibly a Lolium species might be implicated. A system of genetic control of chromosome pairing resembling that of wheat must be suspected for all true allopolyploids. Evidence of the existence of such genetic systems is usually obtained from the breakdown of pairing control in nullisomics or in interspecific hybrids. No nullisomics have been reported in $F$. arundinacea although a monosomic showing a low degree of homoeologous pairing was reported by Jahuar (1975). We have also noted a monosomic of this type in our own material.

The extensive range of meiotic metaphase patterns observed in the progeny of the present set of crosses between a single cultivar of $F$. arundinacea and two half sibs of $L$. perenne is conclusive evidence of the presence of a genetically controlled diploidising system in this natural hexaploid. Clearly the system is being modified by the genotype of $L$. perenne. The variation in the mean number of univalents per pollen mother cell between plants in the present set of hybrids is in the order of 24 , i.e., from 2.1 in 0 B S. $170 \times \mathrm{Lp} 10-1$

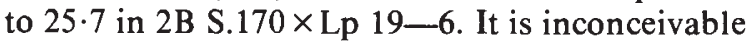
that such large differences in pairing could even partly be due to variation in chromosome differentiation as the only variabie genome is that of $L$. perenne and even that is derived from a common grandparent.

L. perenne Lp19 is known to carry gene or genes capable of suppressing assocation between different genomes of Loliums in synthetic interspecific hybrids at both the diploid and tetraploid level (Taylor and Evans, 1977; Evans and Davies, 1983; Evans and Taing Aung, In Press). B chromosomes are also known to have a similar and additive effect on chromosome pairing in interspecific hybrids. The genotype of $L$. perenne Lp10 on the other hand does not have this marked effect on the level of homoeologous association in compar- able hybrids. Clearly therefore there is a relationship, direct or indirect, between this genetic system first isolated in diploid $L$. perenne and that controlling chromosome pairing in the natural hexaploid $F$. arundinacea. The evidence from the present work together with information already known suggest two possible interpretations of the nature of this relationship. These are:

1. (a) Certain $L$. perenne genotypes such as Lp10 in this experiment are capable of suppressing the activity of the pairing control genes of $F$. arundinacea. Other genotypes do not have this property or are heterozygous (Lp19).

(b) L. perenne $\mathrm{B}$ chromosomes which are known to suppress homoeologous chromosome association in other Lolium interspecific hybrids (Evans and Macefield, 1973) also have the capacity of limiting homoeologous chromosome association between the three genomes of $F$. arundinacea and between the chromosomes of $L$. perenne and those of $F$. arundinacea. In hybrids where the $F$. arundinacea pairing control genes are suppressed by the $L$. perenne genotype the presence of $\mathrm{B}$ chromosomes would compensate, in part at least, for the inactivity of the regulatory genes.

Such a genetic system would have some similarities to those in Triticum and Avena in that genotypes of Aegilops speltoides are capable of suppressing the $P h$ system of $T$. aestivum (Riley, Kimber and Chapman, 1961) and genotypes of Avena longiglumis the diploidising system of hexaploid $A$. sativa (Rajhathy and Thomas, 1972). The result would be a high degree of intergenomic association at meiosis as seen here in $0 \mathrm{~B}$ hybrids involving $L p 10$. Indeed this type of pairing pattern seems to be the norm in $F$. arundinacea $\times L$. perenne. Myers and Hill (1947) recorded $1 \cdot 25^{\mathrm{I}}, 8 \cdot 44^{\mathrm{II}}$ and 2.60 multivalents, Crowder (1953) $2 \cdot 52^{\mathrm{I}}$, $11 \cdot 48^{\mathrm{II}}$ and $2 \cdot 52$ multivalents and Bowman and Thomas (1973) $2 \cdot 6^{\mathrm{I}}, 10 \cdot 7^{\mathrm{II}}$ and $1 \cdot 39$ multivalents in 0B hybrids. On the other hand L. perenne Lp19 carries alleles which are not capable of suppressing the diploidising system of $F$. arundinacea or are themselves actively involved in suppressing homoeologous pairing. This inevitably results in many more unpaired chromosomes.

Superimposed on this is the effect of B chromosomes. The presence of B's reintroduces some degree of suppression of homoeologous association in the Lp10 hybrids and makes it almost complete in the Lp19 hybrids. Again this would be somewhat similar to that observed in $T$. aestivum $\times A e$. speltoides or Ae. mutica containing B chromosomes (Dover and Riley, 1972b). It differs however from the wheat system where B chromo- 
somes had no effect on pairing in the presence of a single dose of the $\mathrm{Ph}$ allele. The $\mathrm{B}$ chromosome of $L$. perenne is seen to be active even in the presence of a single dose of the pairing control alleles of $F$. arundinacea. That this is so is confirmed by the results of Bowman and Thomas (1973) who reported an increase in the number of univalents in a similar hybrid containing a single $\mathrm{B}$ chromosome when compared with a $\mathrm{OB}$ hybrid.

2. The second alternative is that (a) suppression of homoeologous meiotic pairing in $F$. arundinacea is due to the effects of a gene or genes showing additive gene action with a single dose being insufficient to completely suppress the association of homoeologues.

(b) L. perenne genotype Lp19 carries a gene or genes of similar and additive effect to those of $F$. arundinacea. Such alleles would be absent from Lp10 and possibly could be very rare.

(c) The control exercised by $\mathrm{B}$ chromosomes is of a similar nature and additive to that in both F. arundinacea and L. perenne Lp19.

The presence of only one dose of the allele(s) would then lead to a partial breakdown in the strict suppression of homoeologous pairing as indeed has been observed by Malik and Tripathy (1972) in a spontaneous 21 chromosome polyhaploid of $F$. arundinacea. In typical $F$. arundinacea $\times L$. perenne hybrids such as the $S .170 \times \mathrm{Lp} 100 \mathrm{~B}$ plants in the present work the $L$. perenne genotype would contribute no additional alleles capable of pairing control and since there is one additional homoeologous genome the level of pairing would inevitably be higher than in the polyhaploid of Malik and Tripathy. Even so, at 6.4 to 11.4 bivalents per cell it is more than might be expected. The presence of $B$ chromosomes increases the dosage of the pairing control alleles so that substantially fewer homoeologous associations would be seen compared with the corresponding $0 \mathrm{~B}$ hybrids. Introduction of a $L$. perenne genome such as $L$. perenne Lp19 which is known to carry diploidising genes would have a similar effect to the introduction of a B chromosome. Finally Lp19 alleles together with B chromosomes would increase the dosage of the pairing control alleles to a sufficient level to exercise almost complete suppression of homoeologous association as seen in some of the $+B$ hybrids of Lp19. That pairing in some of the other Lp19 hybrids is far from completely suppressed is not unexpected as it is known that this L. perenne genotype is heterozygous for the diploidizing gene(s) (Taylor and Evans, 1977).
Both of these hypotheses are supported, in part at least, by the experimental evidence. However further details of the pairing control system in $F$. arundinacea will have to be resolved before a more precise conclusion can be reached regarding the relationship of the diploidising genetic system identified in diploid $L$. perenne and that present in the hexaploid $F$. arundinacea. The important question of whether the Festuca control system has evolved from that present in some diploids such as $L$. perenne must therefore remain unresolved. However it is a distinct possibility.

Acknowledgements We are grateful to the AFRC for financing this project and to $\mathrm{Mr} \mathrm{D}$. Fallding for technical assistance.

\section{REFERENCES}

BOWMAN, J. G. AND THOMAS, H. 1973. B chromosomes and chromosome pairing in Lolium perenne $\times$ Festuca arundinacea. Nature N.B., 245, 80-81.

CROWDER, L. V. 1953. Interspecific and intergeneric hybrids of Festuca and Lolium. J. of Hered., 44, 195-203.

DOVER, G. A. AND RILEY, R. 1972a. Variation at two loci affecting homoeologous meiotic pairing in Triticum aestivum $\times$ Aegilops mutica hybrids. Nature N.B., 235, 61-62.

DOVER, G. A. AND RILEY, R. 1972b. Prevention of pairing of homoeologous meiotic chromosomes of wheat by an activity of supernumerary chromosomes of Aegilops. Nature, 240, 159-161.

EVANS, G. M. AND MACEFIELD, A. J. 1972. Suppression of homoeologous pairing by B chromosomes in a Lolium species hybrid. Nature N.B., 236, 110-111.

EVANS, G. M. AND DAVIES, E. W. 1983. The genetic control of homoeologous chromosome association in Lolium temulentum $\times$ L. perenne. Chromosoma, 62, 57-67.

EVANS, G. M. AND TAING AUNG 1985. The potential for diploidizing Lolium multiflorum $\times L$. perenne tetraploids. Canad. J. Genet. Cytol. In press.

GAUTHIER, F. M. AND MCGINNIS, R. C. 1968. The meiotic behaviour of a nulli-haploid plant in Avena sativa. Canad. J. Genet. Cytol., 10, 186-189.

ISLAM, A. K. M. R., SHEPHERD, K. W. AND SPARROW, D. H. B. 1981. Isolation and characterization of euplasmic wheat barley addition lines. Heredity, 46, 161-174.

JAHUAR, P. P. 1975. Genetic control of diploid like meiosis in hexaploid tall fescue. Nature, 254, 595-597.

LEWIS, E. J., HUMPHREYS, M. W. AND CATON, M. P. 1980. Disomic inheritance in Festuca arundinacea Schreb. $Z$. Pflzucht., 84, 335-341.

MACEFIELD, A. J. 1976. The control of chromosome pairing at meiosis in Lolium. Ph.D. Thesis, Univ. of Wales.

MALIK, C. P. AND TRIPATHY, R. C. 1970. Mode of chromosome pairing in polyhaploid tall fescue (Festuca arundinacea Schreb.). Zeitschrift fur Biol., 116, 332-339.

MYERS, W. M. AND HILL, H. D. 1947. Distribution and nature of polyploidy in Festuca elatior L. Bull. Torrey Bot. Club, 74, 99-111.

OKAMOTO, M. 1957. Asynaptic effect of chromosome V. Wheat Inf. Serv., 5, 6. 
RAJHATHY, T. AND THOMAS, H. 1972. Genetic control of chromosome pairing in hexaploid oats. Nature N.B., 239, 217-219.

RILEY, R. AND CHAPMAN, v. 1958. Genetic control of cytologically diploid behaviour in hexaploid wheat. Nature, 182, 713-715.

RILEY, R., KIMBER, G. AND CHAPMAN, V. 1961. The origin of the genetic control of diploid like behaviour of polyploid wheat. J. Hered., 52, 22-26.

RILEY, R., CHAPMAN, V. AND MILlER, T. E. 1973. The determination of meiotic chromosome pairing. Proc. 4th Int. Wheat Genet. Symp. (ed. E. R. Sears and L. M. Sears). pp. 731-738.
SEARS, E. R. AND OKAMOTO, M. 1958. Intergenomic chromosome relationships in hexaploid wheat. Proc. Int. Cong. Genet., 2, 258-259.

STEBBINS, G. L., Jr. 1938. Cytological chracteristics associated with the different growth habits of dicotyledons. Amer. $J$. Bot., 25, 189-198.

TAYLOR, I. B. AND EVANS, G. M. 1977. The genetic control of homoeologous chromosome association in Lolium temulentum $\times$ L. perenne. Chromosoma, 62, 57-67.

WALL, A. M., RILEY, R. AND GALE, M. D. 1971. The position of a locus on chromosome $5 \mathrm{~B}$ of Triticum aestivum affecting homoeologous meiotic pairing. Genet. Res. 18, 329-339. 